Hoyle LP, Kyle RG \& Mahoney C, Nurses' views on the impact of mass media on the public perception of nursing and nurse-service user interactions, Journal of Research in Nursing 22 (8), pp. 586-596. Copyright (C) The Authors 2017. Reprinted by permission of SAGE Publications.

\title{
Title: Nurses' views on the impact of mass media on the public perception of nursing and nurse-service user interactions
}

\author{
ABSTRACT \\ Aims: To examine nurses' views on the impact that mass media has on service users and how this \\ affects nurse/service user interactions.
}

Background: Internationally, the mass media is an important source of health information for the public. Media framing therefore exerts considerable influence on the public's perceptions of healthcare professionals and services. However, it is not known how the reporting of health stories by the media impacts the work of front-line nursing staff.

Design: A qualitative interpretivist study using a single case study design.

Methods: Semi-structured interviews with qualified nursing staff $(n=31)$ within a large hospital in the United Kingdom.

Results/Findings: Three key themes: 'scaremongering health stories'; 'negative portrayal of the nursing profession and 'informed service users'. Nurses perceived media framing of health and healthcare services as predominantly negative.

Conclusion: Nurses need greater awareness of how service users receive and respond to health information and how health stories are reported. Closer engagement between health journalists and nurses through 'journalist-in-residence' programmes could enable nurses and journalists to gain greater appreciation of their respective sets of knowledge to support shared and informed decisionmaking between service users and professionals.

Key words 
UK, nurses, mass media, health information, public perception, interactions, qualitative

\section{Article Manuscript \\ INTRODUCTION}

Mass media - including the internet, television, radio and print media - plays an important role in communicating information about health and healthcare services (Atkin \& Wallack 1990; Van

Bekkum \& Hilton 2013). Increased emphasis on service user choice and informed decision-making throughout healthcare systems in developed economies means that the mass media exerts considerable influence on the decisions individuals take about their own and their families' health ( Grilli et al. 2002; Liu \& Priest 2009; Bernabeo \& Holmboe 2013). Healthcare services have also undergone radical shifts underpinned by principles of consumerism and managed care (Lee 2008). As a result, the public are increasingly expected to be 'consumers' of care and to take a greater role in the medical decision-making process (Brashers et al. 2000). Some suggest this expansion of consumerism is inextricably linked to increased availability of free health information to the public (Lowrey \& Anderson 2006). Others predict the so-called 'democratisation' of health knowledge, especially through the internet, will result in more frequent contact between individuals and health professionals (Bylaund et al. 2007; Murray et al. 2003) and that consultations will be quicker due to service users' greater knowledge about their health condition. While numbers of consultations, especially with General Practitioners (GP), in the UK have increased (Baird et al 2016), there is considerable international debate around how the democratisation of knowledge and dawn of consumerism has qualitatively shifted the nature of healthcare interactions between service users and professionals. Little is known about how healthcare professionals perceive these shifts. This study examines nurses' views on the impact that mass media has on service users and how this affects nurse-service user interactions.

\section{Background}


Medical sociologists suggest that health professionals exert dominance by controlling knowledge and expertise of health conditions and so retain power due to service user's relative ignorance (Conrad \& Stults 2010). Although some argue that a gain in knowledge by the general public results in loss of control by health professionals (Lee 2008), others, more optimistically, see new forms of knowledge emerging and expect the public to continue to consult health professionals to interpret information, aiding informed decision-making (Nislon 1997). Increased availability of knowledge may not lead to a decreased dependence on health professionals to discern its authority. Indeed, rising health service use may partly be explained by individuals consulting professionals to clarify uncertainties and difficulties understanding health information (Lee 2008).

Research shows that people obtain most health-related information through a range of media sources (Schwitzer 2004; Rutten et al. 2005; McMullan 2006) that influence perceptions of health risks and behaviours (Hilton et al. 2007; Kitzinger 2009; Hilton et al. 2011). However, research has also found that health information and risks are often presented in an 'alarmist' fashion (Carducci et al. 2011; van Bekkum \& Hilton 2013) and that reports are frequently selective and do not provide the necessary information to enable people to evaluate risk and draw valid conclusions (Rowe et al. 2000; Prue et al. 2003).

Mass media both shapes and is shaped by public attitudes and interests. Media stories about health and healthcare services have proliferated to meet public demand and the internet has widened access to health information (Lee 2008). Yet, questions around quality, authority and authenticity remain. Scrutiny of these questions is especially important in the context of the emergence of the so-called 'post-truth' society built on 'alternative facts'.

Nursing sits at the intersection of managerial and media shifts. As the largest professional group in international healthcare systems, nurses play an important role as both arbiters and advocates of 
informed decision making. Nurses are expected to shape the interactions between service user and hospital, meet service users 'raised expectations' (Anonymous 2011), and deal with the consequences of unmet expectations. However, only one previous study has examined the role mass media has on service user/professional encounters (van Bekkum \& Hilton 2013).

\section{THE STUDY}

Aim

The aim of this paper is to examine nurses' views on the impact that mass media has on service users and how this can affect nurse/service user interactions.

\section{Design}

This qualitative interpretivist (Denzin \& Lincoln 2000) study was grounded in the methodology of adaptive theory (Layder 2006). It did not seek to make claims of generalizability, but was designed to capture commonplace circumstances and conditions for nurses staff within one case study.

\section{Sample/Participants}

Qualified nurses ( $n=31$ ) working within an acute National Health Service (NHS) Hospital in Scotland, United Kingdom (UK) which had an emergency department (ED) were purposively sampled from three specialties: emergency arenas (emergency department, $n=5$; medical assessment, $n=4$; surgical receiving $n=2)$, surgical wards $(n=11)$ and medical wards $(n=9)$. All interviewees were registered nurses who had been qualified for 2->15 years. Inclusion criteria were:

- Must be a qualified/registered nurse

- Contracted to work in speciality area (no bank or agency staff)

- Minimum 2 years' experience as registered nurse

- Minimum 2 years' experience in hospital 
Following established practice when interviewing health professionals (Feldman et al., 2003; Grant 2013; Anonymous 2014), a flexible recruitment approach was used. Some nurses were recruited by the researcher approaching them on the wards inviting participation. For others, Ward Managers disseminated information sheets and provided details of interested participants. All potential interviewees had at least 24 hours to consider before deciding whether to participate and were given an opportunity to ask questions. Written consent was obtained for all participants.

\section{Data collection}

A semi-structured interview guide was revised through piloting with 4 nurses. The final guide included questions asking participants to reflect on the meaning and consequences of consumerism in the NHS and the role of mass media on service user interactions. Interviews were held at the hospital during a three-month period in 2010. A private space for the interviews was used, variously: a visitor/relative room; staff common room; Ward Manager's office; equipment training room; and seminar room. All were distant from the ward thereby offering privacy and freedom from non-urgent interruptions. Interviews were audio-recorded and lasted 22-63 minutes (typically 45 minutes). Audio recordings and anonymised verbatim transcripts were stored on a secure encrypted database.

\section{Ethical considerations}

Ethical approval was obtained from both a university and UK NHS Research Ethics Committee (ref: 09/S0709/75) and the study had all appropriate UK NHS governance clearances.

\section{Data Analysis}


QSR Nvivo 8 (QSR International, Burlington, MA, USA) was used for data management tool for analysis. Thematic analysis (Braun \& Clarke 2006) was conducted in two steps. Preliminary analysis was conducted concurrently with data collection. This enabled continual reflection and informed changes to the probes used in subsequent interviews. Once fieldwork had been completed and as the researcher became familiar with the data through repeated close reading of transcripts a set of thematic categories (Ritchie et al. 2008) were coded. A second 'pass' through the data was then conducted resulting in classification of further themes. This ensured development of thematic categories was an emergent and iterative process and enhanced rigour as coded data was traceable back to the original transcripts.

\section{FINDINGS}

Table 1 shows participant characteristics.

[INSERT TABLE 1 HERE]

Three themes were identified: scaremongering health stories; negative portrayal of the nursing profession; and informed service users.

\section{Scaremongering health stories}

Nurses frequently perceived media reporting of health stories as inaccurate and generally negative:

...and for that one person, 100 people have been through with excellent stories and they're never ever portrayed in the media. It's always negative things like handwashing, that's the media focus, nurses aren't washing their hands and C-diff' is rife and 'MRSA' killed my mum', it's always negative (Nurse 14 , Female, 2-5 years).

\footnotetext{
${ }^{1} \mathrm{C}$-diff is a short term for Clostridium Difficile, a healthcare acquired infection (HAI).

${ }^{2}$ MRSA is a short term for Methicillin-resistant staphylocus Aureus, an HAI.
} 
Nurses felt frustrated by this and believed that the media was unjust in its reporting of nurses and the NHS. Several nurses suggested this resulted in increased workload as they dealt with anxious and fearful service users. Nurses therefore spent longer with individuals attempting to alleviate this fear and anxiety:

Scaremongering ... like the way they put certain headlines in about hospital acquired infections, that has an effect because patients are terrified to come into hospital and they automatically fear the ward as soon as they come in (Nurse 24, Female, 6-10 years).

Most nurses thought press stories were 'a tiny minority of what is going on' (Nurse 26, Female, 3-5 years) and that most positive events were not reported on. Media reporting focused on the negative minority rather that the majority of effective and supportive care.

\section{Negative portrayal of nursing profession}

Nurses felt the nursing profession was represented by the media as negative and this affected the public's views and expectations. This influenced nurses' relationships with service users and relatives, and impacted on their workloads. Staff connected the media, consumerism and public's expectations of the service suggesting it was detrimental to the NHS:

The media very rarely promote or put good practice on the front page of a newspaper, because it's not sexy. MRSA, C. diff outbreaks all that's all sexy, it sells newspapers and everybody likes bad, you know, bad publicity 'look what the NHS are doing now'. And that relates back to consumerism by the public as well, what their expectations are. A lot of that is driven by the media in what's portrayed in the newspapers and on the news as well and if it's going to be negative they're going to come in with a level 
like 'if this happens to me I'm going to sue'. So, it's a vicious circle (Nurse 7, Male, 15+ years).

Many nurses reported that the media portrayed nurses negatively, casting the profession in a poor light. Concern was raised around stories of individuals' failings at other hospitals that meant: 'everyone [all nurses] is tarred with the same brush' (Nurse 24, Female, 6-10 years):

I think they sensationalise, very much so, and wrongly. If there's problems, like the Vale of Leven ${ }^{3}$ outbreak or Beverley Allitt ${ }^{4}$ killing children [...] then, yeah, things have got to be reported. But I think sometimes they just go overboard, and they don't get all the facts and it's not always correct ... it's five-minute news but can last a lifetime. Like all the superbug business, I'm not denying superbugs are a very big problem, although the rates are getting much, much better now and have done for the last couple of years ... And I think the whole media circus is just, and it's made people afraid, it's made people lose faith in a lot, and it's made them much more judgemental I think as well. And I think their expectations in that make it higher, which again puts pressure on (Nurse 10, female, $15+$ years).

Nurses thought the public viewed all nurses and hospitals as the same, and that when accessing services, had a negative view of all staff due to the actions of a few or the inaccuracy of information: 'I think they [the nursing staff] get angry because it's not always accurate information that's on it [the news]' (Nurse 16, Female 6-10 years). Many nurses felt that the media had a role to play in low staff morale. This led to upset, annoyance and frustration and caused difficulties between the relationships

\footnotetext{
${ }^{3}$ An outbreak of C. Difficle in 2007-8 at Vale of Leven Hospital that led to the infection of 55 patients and death of 18 patients was blamed on poor hygiene standards in the hospital.

${ }^{4}$ Beverley Allitt, a nurse, was responsible for the murder of four children and attempted murder of nine others whilst in her care.
} 
staff had with the public and the media. This was also considered to contribute to increased nursing workloads, because more time was spent with individuals on admission. For example, due to negative media portrayal, when relatives (and service users) visited hospital, they were looking for problems, and where found, automatically assumed lapses of good care and standards:

The relatives, as I say, got their knickers in a twist ${ }^{5}$, and, you know [laugh], their backs get up when they come in to see their mum and there's a wee bit of blood on the floor, d'you know, that's just happened - that kind of thing (Nurse 16, Female, 15+ years).

Nurses stressed that media stories attributing blame to nurses did not acknowledge that sometimes it was outside their control, hence the feelings of animosity and resentment.

However, respondent's comments were paradoxical. On the one hand, it was reported that the media caused difficulties for staff. On the other hand, it provided service users with insight which enabled informed decision-making which was considered beneficial. Also, reporting of adverse events within the NHS, helped improve quality of the services and meant the public was empowered: 'it's good because it means that patients and relatives now know what to expect and can comment' (Nurse 1, Female, $15+$ years)

\section{Informed service users}

Many nurses suggested that due to increased access and exposure to media (and particularly the internet) service users were more informed about their health conditions and treatment options. However, this raised public expectations about what the NHS can offer: 'if it's available in America, why can't we have it?' (Nurse 1, Female, 15+ years). Moreover, raised expectations were often directly attributed to increased exposure to information on the internet: 'their (the public) sense of expectation

\footnotetext{
${ }^{5}$ This is a colloquialism which in essence means getting worked up over something without good reason.
} 
is higher because of access to [the] internet' (Nurse 14, Female, 15+ years). Nurses also noted that increased access to information had increased tensions between staff and service users. This was considered a consequence of professional knowledge moving into the public domain:

The internet's played a big part on their rights, their illnesses - they tend to look things up and that does make nursing and probably medicine a lot more difficult, because they expect a certain amount of care that maybe is not suitable for them (Nurse 20, Female, 6-10 years).

Down to consumerism, expectations and rights of patients have increased, they are far more aware - the use of the internet means they are better able to ask for what they think is the right operation/medication etc. they also see inconsistencies e.g. the postcode lottery. People are better educated and more outspoken about their views, some are good some are not. It is because of these types of issues that we practice defensive medicine (Nurse 9, Female, 15+ years).

Nurses often framed the issue as a tension between informed service users versus service user ignorance which was perceived as a power struggle over knowledge. This lead to conflict between nurses and service user/relatives, as the information and treatment offered was often not what was expected:

For medicine and nursing the internet is the worst thing that ever happened, because they have a list of symptoms and they have a list of what should occur. Or what it says that should occur and that's not necessarily what will suit their relative. But getting that across is very often difficult (Nurse 19, Female, 15+ years). 
Consequently, nurses spent considerable time explaining the differences between expectations and reality and interpreting inaccurate information obtained from media sources.

\section{DISCUSSION}

Nurses in our study thought that the media engaged in scaremongering about health, portrayed the nursing profession negatively and that by increasing access to information raised service users' expectations. Combined, this was considered to increase nurses' workloads as time needed to be spent talking to service users (and their families) to ensure that they fully understood their treatment and the role of the nurses and the hospital. It is noteworthy that nurses frame this interaction negatively rather than as an opportunity to interact with and educate service uses. This raises questions about the appropriate role of nurses in engaging and supporting service users with selfsourced health information. Nurses need to consider their role within the changing context of healthcare within western health systems. In the broader context of neoliberalism service users are increasingly encouraged to take responsibility for their own health and management of conditions. This increasing focus on shared decision making, participation and person-centeredness means that the relationship between healthcare professionals and service users is changing. Moreover, due to advances in digital technology access to both information about health issues and personal health data will continue to increase and nurses must be able to engage in meaningful conversations with service users who may be more empowered about their understanding of their health conditions and care. For example, research indicates that people who use the internet to gain health information require more help from health professionals to interpret and understand the information to be able to make choices (Ahmad et al.2006: Lee 2008). Health professionals have a role in advancing service user's knowledge, understanding and decision making (Mayer \& Villaire 2011; Ferguson \& Pawlak 2011). However, this needs to be balanced with the workloads of staff to ensure they can provide the time and support to fulfil this role. 
Moreover, negative framing was perceived by nurses to cause conflict as nurses considered that their knowledge and practices were being questioned and challenged by service users. Consumer rhetoric has acted to redefine service users as customers and reversed historical conceptions of service users as passive recipients of care (Bolton 2004). Service users are now encouraged to make demands and become more active participants in care, challenging professional power and, potentially, leading nurses (and other healthcare professionals) to feel a constraint on their autonomy and authority. Conrad and Stults (2010) have argued that the internet has served as an equaliser allowing individuals to access the same information as experts. Conversely, nurses in our study expressed a sense of challenge to authority as a result of increased questioning from service users prompted by information obtained from the media. Nurses also raised concerns about the validity and reliability of the information that the general public were able to access via the media.

The twin trends of consumerism and democratisation of knowledge have, in nurses' eyes, served to negatively increase the visibility of nursing work. This has raised service users' expectations enabling them to draw comparisons to care provided in other geographical contexts (which may themselves be polarised through media lenses) triggering a redrawing of professional boundaries through challenges to authority. This perceived challenge to authority may explain why nurses in our study considered the media as generally negative. However, to be effective in their role as knowledge-brokers nurses need to engage media representations of their profession and the healthcare services within which they work, as well as with media stories around health that they deemed scaremongering. Indeed, nurses' engagement with the media is critical in an era where fiction is recast as 'alternative fact' and 'post-truth' is rhetorically replacing the lie. Nurses should therefore actively engage with the mediation of their voice and visibility of their practice.

Nurse education has a significant role to play here in shaping how nurses receive and respond to media reports of health conditions and care. Equipping nurses to engage in an effective dialogue with services users who may feel empowered by their own reading and interpretation of media stories to 
ensure that shared decision-making occurs should form part of nursing curricula. Nurse education should therefore provide student nurses with the knowledge and understanding to engage with media reporting, the ability to support service users in critically appraising health information and data in the public domain.

Nurses therefore need to be up-to-date with accurate information and evidence-based practices. To discern fact from fiction in the accounts service users share, nurses need to be confident in their own understanding and ability to consider, critically appraise contextualise and, where required, challenge mass media reports for the general public. Van Bekkum \& Hilton (2013) have reported that media reports were the first point of contact for new or controversial health information among primary care nurses. They noted that there was a delay in dissemination of information from official channels, and that it was easier and quicker for nurses to access media reports. Hilton et al. (2009) also highlight that nurses often turn to media as a source for information. Nurses therefore need to have the skills and time to access primary sources of information and to be able to effectively appraise secondary reporting. However, research has suggested that nurses may not have these skills and there if often not time for staff to engage fully with the evidence (Borglin \& Fagerström (2012), Nilsson et al. (2013)). This research, taken together with the findings of our study, leads us to call for closer engagement between nurses and individuals who commission, write and edit media stories around health and nursing. This might start with increased exposure to media studies during nurse education drawing on expertise within and without the university followed up with on-going professional development of skills to engage and critique media stories post-qualifying. Nursing campuses and clinical settings should also consider hosting journalists through 'journalist-inresidence' schemes to enable shared understanding of both sets of professional knowledges.

\section{LIMITATIONS}


Although no claims to generalizability are made, this study draws on a single case study and therefore findings may not be transferrable to other contexts. Moreover, these finding emerged through a larger PhD study which explored how front-line nurses cope with and resist the demands of the workplace (Hoyle 2011; Hoyle 2014; Hoyle 2014 Hoyle \& Grant 2015). Further comparative research in different healthcare contexts is therefore required.

\section{CONCLUSION}

Nurses in our study viewed media portrayal of their profession as negative and stories about health as scaremongering. This put pressure on nursing workloads by increasing the time nurses spent in their role as knowledge-brokers explaining media stories. It also caused conflict as nurses felt the erosion of professional boundaries and challenges to authority and autonomy. There is a potential risk that the media's role in opening up knowledge about health and healthcare service may result in a gulf in understanding between service users and professionals, and between professionals and the media. Hence, our study concludes that closer engagement between nurses and media organisations is required at each stage of nurses' careers: from the fostering of critical enquiry skills focussed on the media during nurse education, through continual questioning in practice, to reaching shared understanding through schemes that embed journalists in clinical settings. In this way, the priorities of both the media and nursing profession might be better understood, balanced views of both positive and negative issues within healthcare services presented, and the public better placed to make informed decisions about their health. 


\section{REFERENCES}

Ahmad, F., Hudak, P.L., Bercovitz, K., Hollenberg, E., Levinson, W. 2006. Are physicians ready for patients with internet-based health information? Journal of Medical Internet Research, 8(3), e22.

Atkin, C.K. \& Wallack, L., 1990. Mass communication and public health, Newbury Park: Sage.

Bernabeo, E. and Holmboe, E.S. (2013) Patients, providers, and systems need to acquire a specific set of competencies to achieve truly patient-centred care. Health Affairs, 32(2), pp.250-280.

Baird, B., Charles, A., Honeyman, M., Maguire, D., das, P. (2016) understanding Pressures in General Practice. London: The Kings Fund. available from: https://www.kingsfund.org.uk/sites/files/kf/field/field_publication_file/Understanding-GPpressures-Kings-Fund-May-2016.pdf.

Brashers, D.E., Haas, S.M., Klingle, R.S., \& Neidig, J.L. 2000 Collective AIDS activism and individual's perceived self-advocacy in physician-patient communication. Human Communication Research, 26, 372-402.

Bolton, S. C. 2004, "A simple matter of control? NHS hospital nurses and new management", Journal of Management Studies, vol. 41, no. 2, pp. 317-333.

Borglin, G. and Fagerström, C. (2012) Nursing students' understanding of critical thinking and appraisal and academic writing: a descriptive, qualitative study. Nurse Education Practice. 12(6): 356-360.

Bylund, CL., Sabee., C.M., Imes, R.S., \& Sanford, A.A. 2007 Exploration of the construct of realised among patients who talk with their providers about internet information. Journal of Health Communication. 12,1: 17-28.

Carducci, A. et al., 2011. Mass media health information: quantitative and qualitative analysis of daily press coverage and its relation with public perceptions. Patient education and counseling, 82(3), pp.475-8. Available at: http://www.ncbi.nlm.nih.gov/pubmed/21288683 [Accessed March 29, 2016].

Conrad, P. \& Stults, C. 2010, "The internet and the experience of illness," In C. E. Bird et al., eds., The handbook of medical sociology. (6th edn.), Vanderbilt University Press: Tennessee. Pp. 179-191. Ferguson, L.A., and Pawlak, R. 2011 Health literacy: the road to improved health outcomes. Journal of Nurse Practice, 7(2), pp. 123-129.

Denzin, N.K. \& Lincoln, Y.S. 2000 "The discipline and practice of qualitative research", In N.K. Denzin \& Y.S. Lincoln (eds.) Handbook of qualitative research ( $2^{\text {nd }}$ edn.), Sage: London.

Feldman, M. S., Bell, J., \& Berger, M. T. 2003, Gaining Access. A Practical and Theoretical Guide for Qualitative Researchers Altamira Press: Oxford.

Grant, A. 2013. The effect of the use of discretion on occupational therapists' professional identity. British Journal of Occupational Therapy 76(9), pp. 409-417. 
Grilli, R., Ramsay, C. \& Minozzi, S., 2002. Mass media interventions: effects on health services utilisation. The Cochrane database of systematic reviews, (1), p.CD000389. Available at: http://www.ncbi.nlm.nih.gov/pubmed/11869574 [Accessed March 29, 2016].

Hilton, S., Petticrew, M. \& Hunt, K., 2007. Parents' champions vs. vested interests: Who do parents believe about MMR? A qualitative study. BMC Public Health, 7(1), p.42. Available at: http://www.biomedcentral.com/1471-2458/7/42 [Accessed March 29, 2016].

Hilton, S., Bedford, H., Calnan, M. and Hunt, K. 2009. Competency, confidence and conflicting evidence: key issues affecting health visitors' use of research evidence in practice. BMC Nursing, 8(1), pp. 4.

Hilton, S. et al., 2011. School nurses' experiences of delivering the UK HPV vaccination programme in its first year. BMC Infectious Diseases, 11(1), p.226. Available at: http://www.biomedcentral.com/1471-2334/11/226 [Accessed March 29, 2016].

Hoyle, L.P. (2011) New public management and nursing relationships in the NHS. Thesis: University of Stirling.

Hoyle, L.P (2014) Nurses' perception of front line senior managers at the front-line: people working with clipboards. Journal of Advanced Nursing, 70, 11, 2528-2538.

Hoyle, L.P (2014): "I mean obviously you're using your discretion": Nurses use of discretion in policy implementation. Social policy and Society, 13, 2.

Hoyle L.P and Grant, A. (2015) treatment targets in emergency departments: nurses' views of how they affect clinical practice' Journal of Clinical Nursing, 15-16, 2211-2218.

Kitzinger, J., 2009. The media and public risk . London: The Risk and Regulation Advisory Council.

Layder, D. 2006, Understanding social theory, (2nd edn.). Sage: London.

Lee, C.J. 2008. Does the internet displace health professionals? Journal of Health Communication, 13(5), pp. 450-464.

Liu, H. \& Priest, S., 2009. Understanding public support for stem cell research: media communication, interpersonal communication and trust in key actors. Public Understanding of Science, 18(6), pp.704-718. Available at: http://pus.sagepub.com/cgi/doi/10.1177/0963662508097625 [Accessed March 29, 2016].

Lowrey, W. \& Anderson, W.B. 2006 The impact of internet use on the public perception of physicians: a perspective from the sociology of professions literature. Health Communication 19, 2: $125-131$.

Mayer, G. and Villaire, M. 2011 Health literacy: an opportunity for nurses to lead by example. Nursing Outlook, 59(2), 59-60. 
Murray, E., Lo, B., Pollack, L., Donelan, K., Catania, J., Zapert, K. \& tunrer, R. 2003 The impact of health information on the internet on health care and the physician-patient relationship: National U.S. survey among 1,050 U.S physicians. Journal of Medical Internet Research 5(3), e17.

McMullan, M., 2006. Patients using the Internet to obtain health information: how this affects the patient-health professional relationship. Patient education and counseling, 63(1-2), pp.24-8. Available at: http://www.ncbi.nlm.nih.gov/pubmed/16406474 [Accessed March 29, 2016].

Nilsson Kajermo, K., Ailnaghizadeh, H., Falk, U., Wandell, P. and Tornkvist, L. (2014) Psychometric evaluation of a questionnaire and primary healthcare nurses' attitudes towards research and use of research findings. Scand J Caring Sci. 28(1): 173-85

Prue, C.E. et al., 2003. Communication monitoring: shaping CDC's emergency risk communication efforts. Journal of health communication, 8 Suppl 1, pp.35-49; discussion 148-51. Available at: http://www.ncbi.nlm.nih.gov/pubmed/14692571 [Accessed March 29, 2016].

Rowe, G., Frewer, L. \& Sjoberg, L., 2000. Newspaper reporting of hazards in the UK and Sweden. Public understanding of science (Bristol, England), 9(1), pp.59-78. Available at: http://www.ncbi.nlm.nih.gov/pubmed/11624282 [Accessed March 29, 2016].

Rutten, L.J.F. et al., 2005. Information needs and sources of information among cancer patients: a systematic review of research (1980-2003). Patient education and counseling, 57(3), pp.25061. Available at: http://www.ncbi.nlm.nih.gov/pubmed/15893206 [Accessed March 29, 2016].

Schwitzer, G., 2004. Ten troublesome trends in TV health news. BMJ : British Medical Journal, 329(7478), p.1352. Available at: http://www.ncbi.nlm.nih.gov/pmc/articles/PMC534863/.

Van Bekkum, J.E. \& Hilton, S., 2013. Primary care nurses' experiences of how the mass media influence frontline healthcare in the UK. BMC Family Practice, 14(1), p.178. Available at: http://www.biomedcentral.com/1471-2296/14/178 [Accessed March 29, 2016 
